\title{
Identification and molecular docking study of novel cholesterol esterase inhibitory peptides from camel milk proteins
}

\author{
Priti Mudgil, ${ }^{1}$ Bincy Baby, ${ }^{2}$ Ying-Yuan Ngoh, ${ }^{3}$ Ranjit Vijayan, ${ }^{2}$ Chee-Yuen Gan, ${ }^{3 *}$ and Sajid Maqsood ${ }^{1 *}$ \\ ${ }^{1}$ Food Science Department, College of Food and Agriculture, United Arab Emirates University, Al-Ain, 15551, United Arab Emirates \\ ${ }^{2}$ Department of Biology, College of Science, United Arab Emirates University, Al-Ain, 15551, United Arab Emirates \\ ${ }^{3}$ Analytical Biochemistry Research Centre $(\mathrm{ABrC})$, Universiti Sains Malaysia, 11800 USM, Penang, Malaysia
}

\section{ABSTRACT}

Novel bioactive peptides from camel milk protein hydrolysates (CMPH) were identified and tested for inhibition of cholesterol esterase (CEase), and their possible binding mechanisms were elucidated by molecular docking. Papain-generated CMPH showed the highest degree of hydrolysis. All CMPH produced upon enzymatic degradation demonstrated a dramatic enhancement of CEase inhibition compared with intact camel milk proteins, with papain-generated hydrolysate $\mathrm{P}_{9}$ displaying the highest inhibition. Peptide identification and their modeling through PepSite 2 revealed that among 20 potential bioactive peptides in alcalase-generated hydrolysate $\mathrm{A}_{9}$, only 3 peptides, with sequences KFQWGY, SQDWSFY, and YWYPPQ, showed the highest binding toward CEase catalytic sites. Among 43 peptides in 9-h papain-generated hydrolysate $\mathrm{P}_{9}$, 4 peptides were found to be potent CEase inhibitors. Molecular docking revealed that WPMLQPKVM, CLSPLQMR, MYQQWKFL, and CLSPLQFR from $\mathrm{P}_{9}$ hydrolysates were able to bind to the active site of CEase with good docking scores and molecular mechanics-generalized born surface area binding energies. Overall, this is the first study reporting CEase inhibitory potential of peptides generated from milk proteins. Key words: cholesterol esterase, camel milk protein, papain, novel peptide, molecular docking

\section{INTRODUCTION}

Metabolic disorders are becoming a serious health concern for today's society. These metabolic disorders are not only an economic burden but also are a leading cause of mortality globally. Hyperlipidemia is one such health concern that is characterized by elevated levels of triglycerides and cholesterol in the blood. Increased

Received February 21, 2019.

Accepted July 28, 2019.

*Corresponding authors: sajid.m@uaeu.ac.ae and cygan@usm.my levels of cholesterol are not only implicated in the development of cardiovascular complications but also act as risk factors for other diseases such as obesity, diabetes, and hypertension. Incidences of obesity and hyperlipidemia are a leading concern globally as well as in the United Arab Emirates. Physiologically understanding the molecular mechanism for development of obesity and hyperlipidemia is very complex with a myriad of risk factors associated with it (Fox et al., 2016). However, 2 enzymes in particular (pancreatic lipases and cholesterol esterase, CEase) are almost always implicated in their development and associated complications (Adisakwattana et al., 2012). Inhibition of both enzymes has been targeted by the scientific arena worldwide for the development of antiobesity and antihypercholesteremic drugs (Deck and Vander Jagt, 2000). Normally, the human diet consists of cholesterol esters, which are poorly absorbed in the intestine, and cholesterol esterase, a polymeric enzyme produced from acinar cells of the pancreas, plays a pivotal role in hydrolyzing dietary cholesterol esters, thereby producing cholesterol and free fatty acids. These unesterified cholesterols and free fatty acids then can be easily absorbed by the intestine into the blood stream, leading to development of hypercholesterolemia (Adisakwattana et al., 2010). Several synthetic compounds have been developed over the past decade that serves as inhibitors for CEase activity but are sometime associated with serious adverse effects. Hence, natural inhibitors of CEase are much sought after (Su et al., 2016).

Moreover, increased awareness among consumers about the association between diet and health is pushing the demand for nutraceuticals that not only provide nutrition but also impart health benefits to the consumers. Milk proteins, besides being nutritionally rich, also harbor peptide sequences that are capable of modulating specific physiological functions and are known as bioactive peptides (Iwaniak et al., 2014). These peptides are known to exert innumerable beneficial functions in the host system such as mineral-binding, antimicrobial, antihypertensive, immunomodulatory, anticancerous, 
antidiabetic, antithrombotic, and antioxidant activities, with potential applications in formulation of functional foods and nutraceuticals (Korhonen, 2009; Mudgil et al., 2019). Up until now, bovine milk proteins were the primary investigated source for these biologically active peptides that are reported to have various enzyme inhibitory activities, thus exhibiting nutraceutical potential (Nongonierma and FitzGerald, 2014). However, milk proteins from different species (e.g., sheep, goat, mare, camel, and donkey), due to their high genetic and chemical variability among proteins, might produce a novel and diverse range of bioactive peptides with varied bioactive properties (Tulipano et al., 2012; Al-Shamsi et al., 2018).

Traditionally, camel milk has been used to treat various metabolic disorders and gastrointestinal problems. Some recent scientific investigations on camel milk and their hydrolysates have elucidated their potential in inhibiting various enzymes (dipeptidyl peptidase IV, $\alpha$-glucosidase, $\alpha$-amylase, and pancreatic lipase) related to metabolic disorders (Jafar et al., 2018; Kamal et al., 2018; Mudgil et al., 2018; Nongonierma et al., 2018). Recently, for the first time, camel whey hydrolysates produced upon hydrolysis by gastric and pancreatic enzymes have been reported to inhibit CEase and pancreatic lipase activities (Jafar et al., 2018). However, the peptide sequence responsible for such a bioactive property has not been identified yet, thus leaving a scope for further explorations. In addition, different proteolytic enzymes can exert distinct specificity toward proteins, thereby releasing varied peptides with different molecular weights, sizes, and AA sequences that render diverse physicochemical and biochemical properties (Siow and Gan, 2016). Therefore, in the current study, 2 serine and 1 cysteine protease (i.e., alcalase, bromelain, and papain) were used for hydrolysis of camel milk proteins. The hydrolysates generated were characterized from a biochemical perspective using degree of hydrolysis (DH), and their potential inhibitory properties toward CEase were assessed. Peptide identification was carried out using a liquid chromatography MS linear trap quadrupole orbitrap system, and their binding mechanism at the active site of CEase enzyme through molecular docking was also carried out.

\section{MATERIALS AND METHODS}

\section{Chemicals and Reagents}

Enzymes such as alcalase (EC 3.4.21.14; source $=$ Bacillus licheniformis), bromelain (EC 3.4.22.33; source $=$ pineapple stem), papain (EC 3.4.22.2; source $=$ papaya latex), cholesterol esterase (EC 3.1.1.13; source $=$ porcine pancreas $), p$-nitrophenyl butyrate, o-phthaldialdehyde, formic acid, acetonitrile (HPLC grade), methanol (HPLC grade), sodium tetra-borate, $\beta$-mercaptoethanol, SDS, and trizma base were purchased from Sigma Aldrich (St. Louis, MO). All other chemicals and solvents were purchased from $\mathrm{BDH}$ Middle East (Dubai, United Arab Emirates) and were of analytical grade.

\section{Milk Samples and Enzymatic Hydrolysis of Camel Milk Proteins}

Fresh camel milk from 3 different healthy camels (Camelus dromedarius) of same the breed was procured from Al Ain Dairy Farm, United Arab Emirates. The samples were immediately transferred to the laboratory at the Food Science Department, United Arab Emirates University, under chilled conditions. The camel milk was skimmed twice by centrifugation at 3,500 $\times g$ for 15 min at $4^{\circ} \mathrm{C}$. The protein content of milk samples was estimated using bicinchoninic acid assay and was adjusted to $4.0 \% \mathrm{wt} / \mathrm{vol}$ using deionized water, and hydrolysis was carried out using 3 different food grade enzymes [i.e., alcalase, bromelain, or papain; enzyme/ substrate $(\mathbf{E} / \mathbf{S})$ ratio 1:100] in triplicate (3 different batches) at $50^{\circ} \mathrm{C}$ under constant stirring in a water bath. One portion of skimmed camel milk was kept as control, and the other portions were adjusted to $\mathrm{pH} 8$ for alcalase and $\mathrm{pH} 7$ for bromelain and papain. Hydrolysate samples were taken after every $3 \mathrm{~h}$ up to $9 \mathrm{~h}$, and the enzymatic reaction was stopped by heating samples at $100^{\circ} \mathrm{C}$ for $10 \mathrm{~min}$. The samples were centrifuged at a speed of $10,000 \times g$ for $15 \mathrm{~min}$ at $4^{\circ} \mathrm{C}$, and the supernatant was collected and stored at $-20^{\circ} \mathrm{C}$ until further analysis, which was carried out within 3 wk. The potential hydrolysates produced by all 3 enzymes at $9 \mathrm{~h}$ of hydrolysis time were freeze-dried and processed for peptide identification.

\section{Characterization of Camel Milk Protein Hydrolysate: $\mathrm{DH}$}

The DH was analyzed using a previously described method of Al-Shamsi et al. (2018) and calculated using the following Equation 1 as described by Nielsen et al. (2001).

$$
\mathrm{DH} \%=\left(h / h_{\mathrm{tot}}\right) \times 100,
$$

where $h_{\text {tot }}$ was the total number of peptide bonds per protein equivalent and $h$ was the number of hydrolyzed bonds, which was determined by using $h=\left(\right.$ SerineNH $_{2}$ $-\beta) / \alpha$, where $\alpha$ (intercept on the $\mathrm{y}$-axis of a regression line), $\beta$ (slope of a regression line), and $h_{\text {tot }}$ values were $1.039,0.383$, and $8.2 \mathrm{mEq} / \mathrm{g}$ of protein, respectively. 


\section{CEase-Inhibition Assay} by a Spectrophotometric Method

The CEase inhibition was assayed using a modified method as described by Adisakwattana et al. (2012). The test samples (final protein concentration of $10-250 \mu \mathrm{g} / \mathrm{mL})$ were incubated with a substrate (50 $\mu \mathrm{L}$ ) containing $5 \mathrm{~m} M p$-nitrophenyl butyrate in 100 $\mathrm{m} M$ sodium phosphate buffer, and $100 \mathrm{~m} M \mathrm{NaCl}$ in a 96-well microtiter plate. The reaction was initiated by adding $50 \mu \mathrm{L}$ of porcine pancreatic cholesterol esterase $(5 \mu \mathrm{g} / \mathrm{mL})$. After incubation for $30 \mathrm{~min}$ at $37^{\circ} \mathrm{C}$, the reaction was terminated by addition of $1 \mathrm{M} \mathrm{HCl}$. The $p$-nitrophenol released from enzymatic hydrolysis of $p$-nitrophenyl butyrate was spectrophotometrically determined at $405 \mathrm{~nm}$ using a microplate reader, and percent inhibition of CEase activity was calculated as follows:

$$
\begin{gathered}
\% \text { CEase inhibition }= \\
\{1-[(C-D) /(A-B)]\} \times 100,
\end{gathered}
$$

where $A$ (control) was the absorbance in the presence of enzyme and without test sample; $B$ (control blank) was the absorbance without enzyme and test sample; $C$ (reaction) was the absorbance with enzyme and test sample; and $D$ (reaction blank) was the absorbance with test sample but without enzyme. The CEase halfmaximal inhibitory concentration $\left(\mathbf{I C}_{50}\right)$ values were determined by plotting the percentage inhibition as a function of the test compound concentration expressed in micrograms of protein equivalents per milliliter.

\section{Peptide Identification and Sequencing by the Liquid Chromatography MS-Linear Trap Quadrupole Orbitrap System and Bioinformatics Analysis}

Peptide sequencing for selected 9-h hydrolysates $\left(\mathrm{A}_{9}, \mathrm{~B}_{9}\right.$, and $\left.\mathrm{P}_{9}\right)$ was conducted using a Thermo LTQ/ Orbitrap fusion mass spectrometer (Thermo Scientific, San Jose, CA) as previously described by Mudgil et al. (2018). The list of peptides obtained was subsequently screened using the Peptide Ranker web server (http:/ /bioware.ucd.ie/). Peptides with a score greater than 0.80 were designated as potentially bioactive peptides and subjected to novelty check using a database search software [i.e., BIOPEP (http://www.uwm.edu.pl/ biochemia/index.php/en/biopep), PeptideDB (http:// www.peptides.be/), SwePep (http://www.swepep.org/ ), and EROP-Moscow (http://erop.inbi.ras.ru/)]. This was followed by screening using PepSite 2 (Trabuco et al., 2012) to predict the CEase [Research Collaboratory for Structural Bioinformatics (RSCB) Protein Data
Bank (https://www.rcsb.org/) ID: 1AQL-b; source = Bos taurus] inhibitory potentials. The selection of the enzyme inhibitory peptides was performed according to the significance of binding $(P<0.05)$ and the number of potential binding sites.

\section{Molecular Docking of Selected Peptides with CEase Enzyme}

The 3-dimensional structure of CEase (RCSB Protein Data Bank ID: 1AQL-b) was downloaded from the RCSB Protein Data Bank. Proteins were prepared with the Protein Preparation Wizard of the Schrodinger Suite (Schrödinger Suite 2016-4: Protein Preparation Wizard; Schrödinger LLC, New York, NY) to remove unwanted water molecules, add and optimize hydrogen bonds, simplify multimeric complexes, create disulfide bonds, assign bond orders properly, adjust ionization states, and fix the orientation of disoriented groups. The preprocessed structures were then optimized and minimized to generate geometrically stable structures (Sastry et al., 2013).

Active Site Identification and Grid Generation. The PepSite 2 web server was used to predict peptide-binding sites in protein structures (Trabuco et al., 2012). Receptor grids were generated for the prepared protein structures so that peptides bind within the predicted active site. Receptor grids were generated with default values for van der Waals scaling factor (1.00) and charge cutoff (0.25). A cubic search space, centered on the centroid of the active site residues predicted by PepSite 2, was generated for each receptor.

Peptide Docking. The Glide standard precision docking method was used to dock peptides into the prepared protein or enzyme structures (Friesner et al., 2004). Interaction of CEase and 4 potential peptides (highest protein-peptide binding free energy; CLSPLQFR, CLSPLQMR, MYQQWKFL, and WPMLQPKVM) was demonstrated by docking experiments. Peptides were docked starting from multiple random conformations, which were generated by the ConfGen algorithm (Watts et al., 2010). The poses were partially optimized using the standard OPLS_2005 (Banks et al., 2005) molecular mechanics force field (standard precision minimization). Ten representative peptide conformations were selected after clustering of conformers. Finally, all 10 poses were subjected to postdocking minimization in the gridded protein field. Top poses were rescored and ranked by the GlideScore scoring function (Friesner et al., 2004). The best-docked pose with lowest GlideScore value was recorded for each peptide.

Binding Energy Calculation. The standard precision docking poses were subjected to molecular me- 
chanics-generalized born surface area (MM-GBSA) to predict protein-peptide binding free energy in an implicit solvent model. Schrodinger Prime with OPLS _2005 force field and the VSGB 2.0 implicit solvent model (Li et al., 2011; Schrödinger, 2014) were used for the MM-GBSA calculations, where receptor was treated rigidly and the peptide flexible.

\section{Statistical Analysis}

Camel milk protein hydrolysates were generated in 3 batches (triplicate) for each enzyme applied. All data were subjected to one-way ANOVA using SPSS 24.0 software (SPSS Inc., Chicago, IL). Significant treatment means were separated by Tukey's new multiple range test at significance level of 0.05 .

\section{RESULTS AND DISCUSSION}

\section{$D H$}

Characterization of the protein hydrolysates produced by different enzymes for various time intervals is an important requirement for controlling the hydrolysis process to a certain degree at which high bioactive properties of the resulting hydrolysates are retained. The DH values for all hydrolysates are shown in Table 1 . The results showed that upon hydrolysis with 3 different enzymes, a progressive increase in $\mathrm{DH}$ values was found for all hydrolysates at corresponding time intervals of 3 , 6 , and $9 \mathrm{~h}$. After $9 \mathrm{~h}$ of hydrolysis, maximum $\mathrm{DH}$ was found in the papain-generated hydrolysates, followed by bromelain- and alcalase-generated hydrolysates. Papain had a strong effect on hydrolysis of camel milk proteins, which displayed DH values of $43.88,72.15$, and $81.01 \%$ after 3,6 , and $9 \mathrm{~h}$ of hydrolysis, respectively, whereas for alcalase-generated hydrolysates the $\mathrm{DH}$ values increased to $8.84,10.93$, and $16.75 \%$ after 3,6 , and 9 h of hydrolysis. A previous study on camel milk proteins also reported the $\mathrm{DH}$ value of $69.6 \%$ upon simulated gastrointestinal digestion conditions (Tagliazucchi et al., 2016). However, the DH values obtained in the present study are significantly greater than those obtained in bovine milk as reported in previous studies (Jrad et al., 2014; Nongonierma et al., 2017). This could be because of high susceptibility of camel milk proteins toward the enzymatic hydrolysis compared with bovine milk proteins (Salami et al., 2008). All enzymes displayed significant $(P<0.05)$ variation in $\mathrm{DH}$, which could be due to differential specificity of enzymes toward camel milk proteins as substrate and rate of the reaction carried by each enzyme (Dryakova et al., 2010). These results are attributed to the preferential cleavage of the enzyme used. Cleavage sites of alcalase
Table 1. Cholesterol esterase (CEase) inhibitory activity $\left(\mathrm{IC}_{50}\right)$ of camel milk protein (CMP) and hydrolysates obtained by alcalase $\left(\mathrm{A}_{3-9}\right)$, bromelain $\left(\mathrm{B}_{3-9}\right)$, and papain $\left(\mathrm{P}_{3-9}\right)$ hydrolysis ${ }^{1}$

\begin{tabular}{lcc}
\hline Sample & $\begin{array}{c}\text { Degree of } \\
\text { hydrolysis }^{2}(\%)\end{array}$ & $\begin{array}{c}\text { CEase inhibitory } \\
\text { activity }\left(\mathrm{IC}_{50}\right) \\
(\mu \mathrm{g} \text { of protein equivalent) }\end{array}$ \\
\hline CMP & $8.84 \pm 0.62^{\mathrm{d}}$ & $149.01 \pm 4.52^{\mathrm{h}}$ \\
$\mathrm{A}_{3}$ & $50.36 \pm 0.57^{\mathrm{d}}$ \\
$\mathrm{A}_{6}$ & $10.93 \pm 0.64^{\mathrm{d}}$ & $57.25 \pm 0.75^{\mathrm{e}}$ \\
$\mathrm{A}_{9}$ & $16.75 \pm 0.58^{\mathrm{cd}}$ & $42.36 \pm 0.86^{\mathrm{c}}$ \\
$\mathrm{B}_{3}$ & $12.66 \pm 1.01^{\mathrm{d}}$ & $91.10 \pm 3.20^{\mathrm{h}}$ \\
$\mathrm{B}_{6}$ & $22.72 \pm 0.17^{\mathrm{cd}}$ & $75.01 \pm 0.82^{\mathrm{f}}$ \\
$\mathrm{B}_{9}$ & $35.01 \pm 3.74^{\mathrm{b}}$ & $77.63 \pm 0.02^{\mathrm{f}}$ \\
$\mathrm{P}_{3}$ & $43.88 \pm 2.42^{\mathrm{b}}$ & $37.04 \pm 0.77^{\mathrm{b}}$ \\
$\mathrm{P}_{6}$ & $72.15 \pm 4.70^{\mathrm{a}}$ & $44.69 \pm 0.51^{\mathrm{c}}$ \\
$\mathrm{P}_{9}$ & $81.01 \pm 5.52^{\mathrm{a}}$ & $32.43 \pm 0.60^{\mathrm{a}}$ \\
\hline
\end{tabular}

${ }^{\mathrm{a}-\mathrm{h}}$ Within a column, values with different superscripts are significantly different among the different hydrolysates $(P<0.05)$.

${ }^{1}$ Values represent means $\pm \mathrm{SD}(\mathrm{n}=3)$.

${ }^{2}$ Degree of hydrolysis from Mudgil et al. (2018), with reprint permission from Elsevier.

are located in areas with a high density of hydrophobic AA, whereas bromelain and papain specifically cleave at AA adjacent to lysine, arginine, and phenyl-alanine, and bromelain preferred AA next to lysine, arginine, phenylalanine, and tyrosine (Jung et al., 2016).

Hydrolysates produced at $9 \mathrm{~h}$ by different enzymes $\left(\mathrm{A}_{9}, \mathrm{~B}_{9}, \mathrm{P}_{9}\right)$ were also characterized by using reversedphase HPLC (data not shown) as described in our previous study (Mudgil et al., 2018). Upon hydrolysis with different enzymes for $9 \mathrm{~h}$, all the peaks for major proteins such as $\kappa-\mathrm{CN}, \beta-\mathrm{CN}$, and $\alpha$-LA were completely hydrolyzed, and newer shorter peptides eluted over a wide range of elution time (0.9 to $5.0 \mathrm{~min}$ ) were generated (Mudgil et al., 2018). After $9 \mathrm{~h}$ of hydrolysis, some traces of $\alpha-\mathrm{CN}$ were still retained in alcalase-generated hydrolysates $\left(\mathrm{A}_{9}\right)$, whereas for bromelain-generated $\left(\mathrm{B}_{9}\right)$ and papain-generated $\left(\mathrm{P}_{9}\right)$ hydrolysates, complete degradation of $\alpha$-CN was observed (Mudgil et al., 2018). These results agreed with the DH values (Table 1) obtained for all 3 enzymes at $9 \mathrm{~h}$ of hydrolysis, where papain hydrolysates showed maximum $\mathrm{DH}$ followed by bromelain and alcalase.

\section{CEase Inhibitory Activity of CMPH}

A high level of cholesterol in otherwise healthy individuals remains the major risk factor for the development of cardiovascular diseases and related complications. Therefore, the primary target of antiobesity therapies is to reduce the level of serum low-density lipoprotein cholesterol (Ikeda et al., 2002). Cholesterol esterase is the most important enzyme responsible for hydrolysis of cholesterol esters to free fatty acids and cholesterol from dietary fat and their subsequent absorption by en- 
Table 2. Potential binding sites between identified bioactive peptides and cholesterol esterase (CEase) using PepSite 2

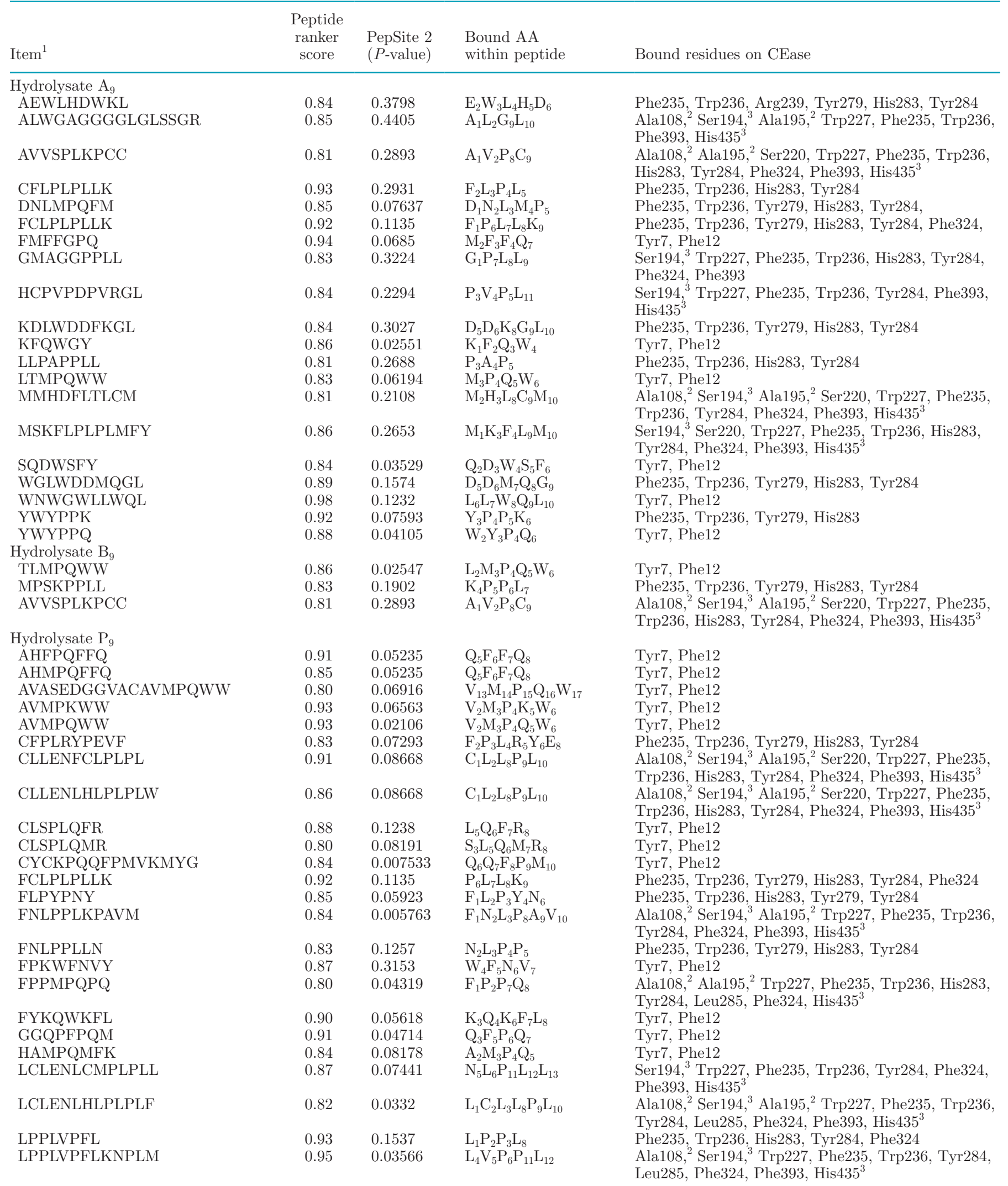


Table 2 (Continued). Potential binding sites between identified bioactive peptides and cholesterol esterase (CEase) using PepSite 2

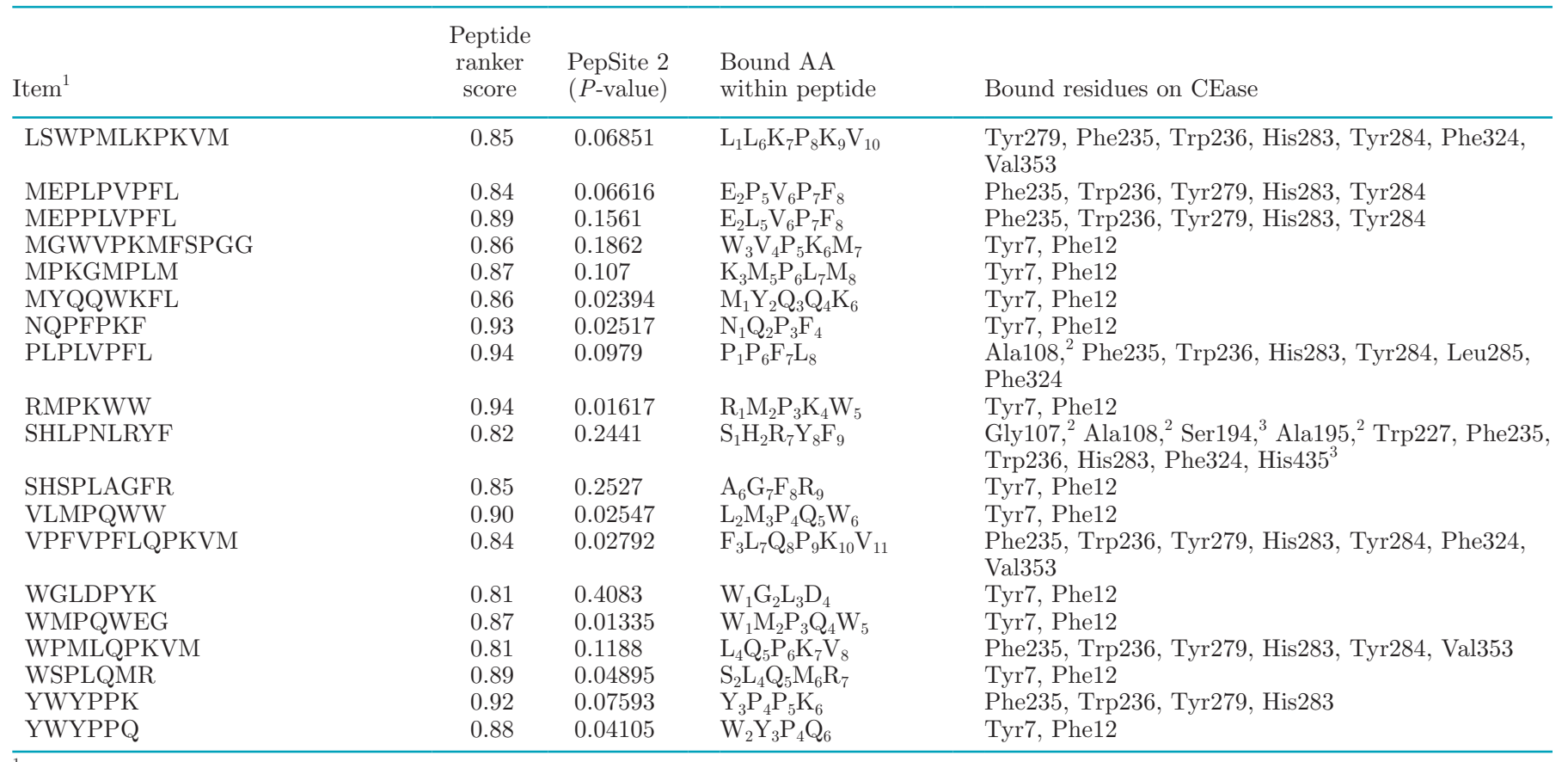

${ }^{1} \mathrm{~A}_{9}=$ alcalase $9 \mathrm{~h}, \mathrm{~B}_{9}=$ bromelain $9 \mathrm{~h}$, and $\mathrm{P}_{9}=$ papain $9 \mathrm{~h}$.

${ }^{2}$ Substrate binding site of CEase.

${ }^{3}$ Catalytic site of CEase.

terocytes (Heidrich et al., 2004). Controlled inhibition of CEase can lead to beneficial effects in overweight and obese individuals (Singh et al., 2017). The inhibition of CEase was tested for camel milk protein and all hydrolysates produced in the present study, and results measured in terms of CEase $\mathrm{IC}_{50}$ are presented in Table 1.

Overall, the CEase $\mathrm{IC}_{50}$ of $149.50 \mu \mathrm{g}$ of protein equivalent was observed for intact camel milk protein. The hydrolysis of camel milk protein via 3 enzymes at different time intervals resulted in a significant $(P<0.05)$ increase in inhibition of CEase activity as observed by the reduction in $\mathrm{IC}_{50}$ values. The $\mathrm{CEase} \mathrm{IC}_{50}$ value for alcalase hydrolysates (i.e., $\mathrm{A}_{3}, \mathrm{~A}_{6}$, and $\mathrm{A}_{9}$ ) was found to be $50.36,57.25$, and $42.36 \mu \mathrm{g}$ of protein equivalent, respectively. Comparatively, bromelain-produced hydrolysate exhibited less potent inhibitory activity against CEase, with a CEase- $\mathrm{IC}_{50}$ value of 91.10, 75.01, and $77.63 \mu \mathrm{g}$ of protein equivalent for $\mathrm{B}_{3}, \mathrm{~B}_{6}$, and $\mathrm{B}_{9}$, respectively. Overall, papain-generated hydrolysates $\mathrm{P}_{3}$ and $\mathrm{P}_{9}$ were found to be the most potent CEase inhibitory hydrolysates, with an $\mathrm{IC}_{50}$ value of 37.04 and 32.43 $\mu \mathrm{g}$ of protein equivalent, respectively. Interestingly, CEase $\mathrm{IC}_{50}$ decreased for $\mathrm{B}_{6}$ in comparison with $\mathrm{B}_{3}$ and then again increased for $\mathrm{B}_{9}$, suggesting the decrease in CEase inhibitory activity upon prolonged hydrolysis for $9 \mathrm{~h}$. However, for alcalase- and papain-generated hydrolysates, an opposite trend was observed, where
CEase- $\mathrm{IC}_{50}$ values declined during first $3 \mathrm{~h}$ of hydrolysis, showed a substantial increase at $6 \mathrm{~h}$, and then again culminated to their lowest level at $9 \mathrm{~h}$ of hydrolysis. These results are attributed to the structural and sequential differences between the peptides produced at a different time of hydrolysis. A similar pattern was observed by Connolly et al. (2015) for angiotensin I converting enzyme inhibitory activities of hydrolysates obtained from hydrolysis of brewers' spent grain protein isolate. In their study, Connolly et al. (2015) observed that during the first $15 \mathrm{~min}$ of hydrolysis, angiotensin I converting enzyme inhibition increased before showing a declination at 30 min and then again an increase at 60,120 , and $180 \mathrm{~min}$ of hydrolysis.

Although direct studies regarding the role of milk proteins or peptides in inhibiting CEase are scarce, various reports suggested the potential of bovine and other milk protein hydrolysates in regulation of cholesterol levels (Nagaoka et al., 2001). Bernstein et al. (1977) reported that bovine milk inhibited cholesterol biosynthesis up to $72 \%$ via inhibition of acetyl CoA enzyme. Similarly, Nagaoka et al. (2001) isolated a hypocholesterolemic peptide named lactostatin (IIAEK) by trypsin degradation of bovine whey protein $\beta$-LG, which was found to be more potent than a known anti-hyper-cholesterolemic drug Sitosterol. Similarly, soystatin (VAWWMY) was derived from soya protein glycinin by pepsin hydrolysis (Nagaoka et al., 1999). 
Table 3. Docking scores, binding energies, and interacting residues of cholesterol esterase [CEase; Research Collaboratory for Structural Bioinformatics (RSCB) Protein Data Bank (https://www.rcsb.org/) ID: 1AQL] complexes

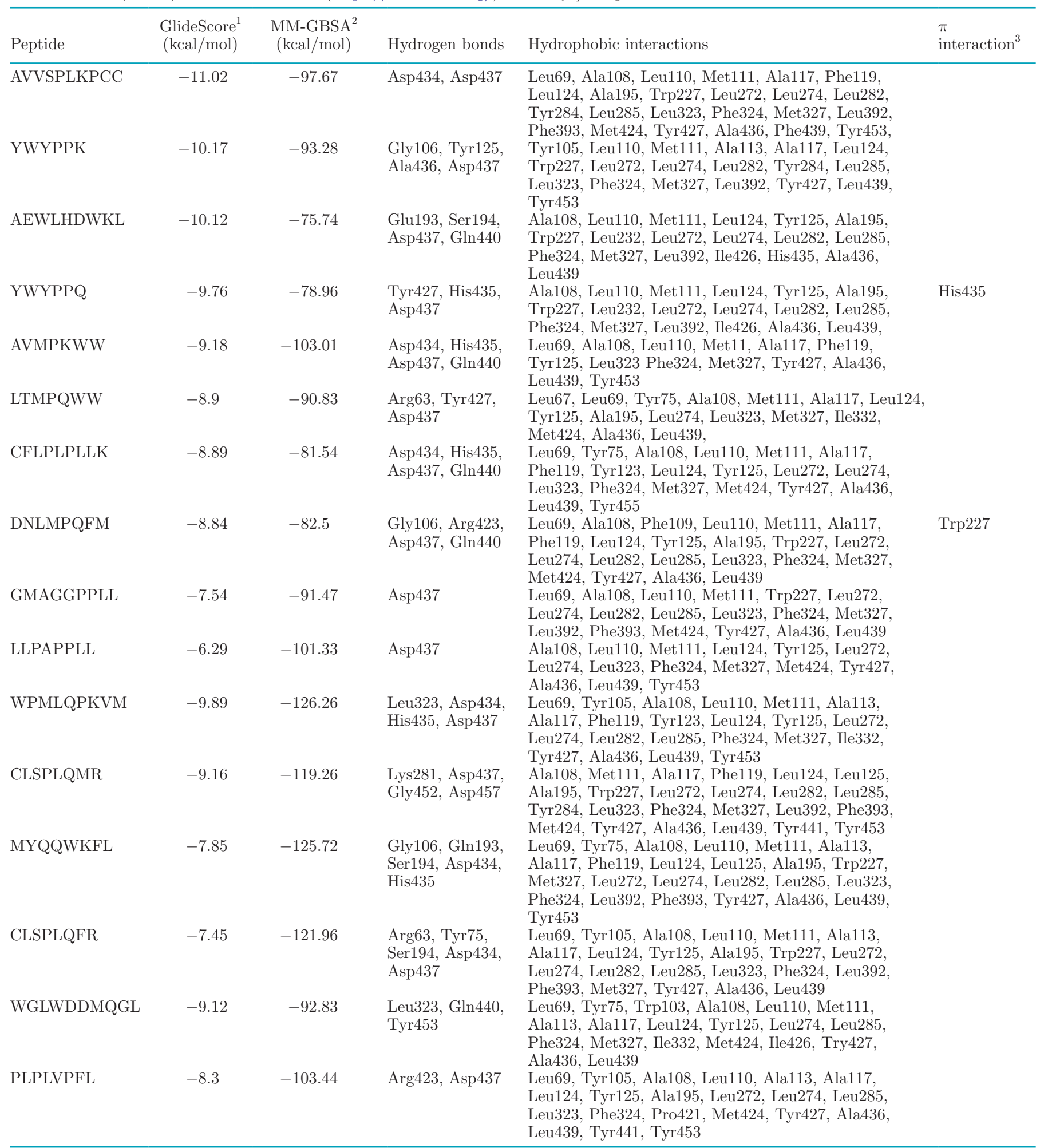

${ }^{1}$ GlideScore scoring function (Friesner et al., 2004).

${ }^{2} \mathrm{MM}-\mathrm{GBSA}=$ molecular mechanics-generalized born surface area.

${ }^{3} \pi$ Interaction $=$ interaction between an electron-rich $\pi$ system and a cation or another $\pi$ system. 
Both peptides (lactostatin and soystatin) were shown to inhibit cholesterol absorption through a pathway similar to CEase inhibitory substances. In another study conducted on alcalase-derived soya protein hydrolysate, a peptide with AA sequence of WGAPSL was found to inhibit the cholesterol micellar solubility (Zhong et al., 2007). Recently, CEase inhibitory potential of camel whey hydrolysates derived from digestion of camel whey proteins using trypsin, pepsin, and chymotrypsin was also reported by Jafar et al. (2018). It was found that pepsin- and chymotrypsin-generated hydrolysates had greater CEase inhibitory properties than chymotrypsin-generated hydrolysates. To our knowledge, until now no study has been published on the identification of peptides from milk proteins of any species for their CEase inhibitory potential. Hence, the present report laid the foundation suggesting potent CEase inhibition of CMPH, which needs further elucidation regarding efficiency under varied in vitro and in vivo conditions.

\section{Identification and Molecular Docking of CEase Inhibitory Peptides from Selective Potential Hydrolysates}

Cholesterol esterase is known as a bile salt-activated lipase, which could hydrolyze cholesterol esters, fatsoluble vitamins, triglycerides, and phospholipids. This enzyme belongs to the $\alpha / \beta$-hydrolase fold family, and its active site contains the catalytic triad, which involves
Ser194, Asp320, and His435, as well as the oxyanion hole (Gly107, Ala108, and Ala195) that forms a tetrahedral intermediate in the active site of CEase, which is crucial for its catalytic function (John et al., 2011). Hydrolysis of cholesterol ester in the lumen of the small intestine is catalyzed by CEase, which releases free cholesterol that mixes with cholesterol contained in bile secretions to form the pool of absorbable cholesterol (Myers et al., 1955). Inhibitors of CEase may provide an efficient strategy to reduce the bioavailability of dietary cholesterol derived from cholesterol esters and may limit the absorption of free cholesterol.

The CMPH produced by different enzymes after $9 \mathrm{~h}$ of hydrolysis $\left(\mathrm{A}_{9}, \mathrm{~B}_{9}\right.$, and $\left.\mathrm{P}_{9}\right)$ were selected and further subjected to identification of the peptide sequence. Overall, 471, 317, and 808 peptides were identified in hydrolysates $\mathrm{A}_{9}, \mathrm{~B}_{9}$, and $\mathrm{P}_{9}$, respectively (Supplemental Table S1; https://doi.og/10.3168/jds.2019-16520). Classification of the identified peptides into highly bioactive peptides was done based on their average local confidence value of at least $80 \%$, and these peptides were represented as potentially biologically active peptides. Thereon, the potential bioactive peptides among the sequenced peptides were shortlisted based on peptide ranker score of $>0.80$. A complete list of peptides having a peptide ranker score of $>0.8$ is displayed in Table 2. A total of 20,3, and 43 peptides, respectively, were qualified (peptide ranker score of $>0.8$ ) to be bioactive peptides in hydrolysates $\mathrm{A}_{9}, \mathrm{~B}_{9}$, and $\mathrm{P}_{9}$ (Table 2). Table 2 also shows the $P$-value and the potential
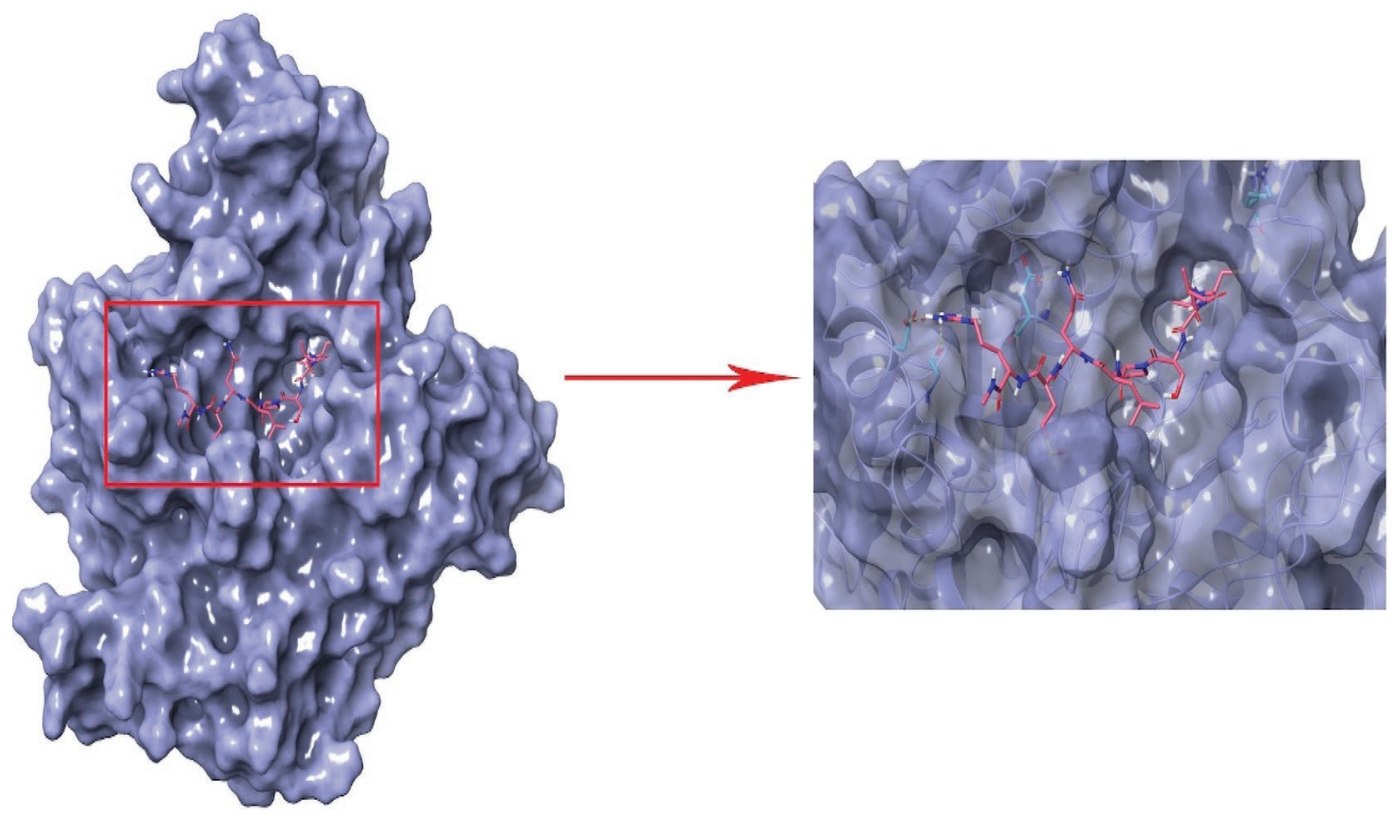

Figure 1. The active site of cholesterol esterase (CEase) is highlighted in the rectangular box, and a closer look at the interaction of peptide CLSPLQMR in the active site of CEase is given. 
binding sites of the identified peptides in $\mathrm{A}_{9}, \mathrm{~B}_{9}$, and $\mathrm{P}_{9}$ hydrolysates with CEase.

The present study showed that CMPH were able to generate potent bioactive peptides that can significantly bind to the active site of CEase, thus having the potential of inhibiting it. Results obtained using PepSite 2 (Trabuco et al., 2012; Table 2) show that KFQWGY, SQDWSFY, and YWYPPQ in $\mathrm{A}_{9}$; TLMPQWW in $\mathrm{B}_{9}$; and AVMPQWW, CYCKPQQFPMVKMYG, FNLP-
PLKPAVM, FPPMPQPQ, GGQPFPQM, LCLENLHLPLPLF, LPPLVPFLKNPLM, MYQQWKFL, NQPFPKF, RMPKWW, VLMPQWW, VPFVPFLQPKVM, WMPQWEG, WSPLQMR, and YWYPPQ in $\mathrm{P}_{9}$ showed significant $(P<0.05)$ binding to CEase (Table 2). However, among these peptides, only FNLPPLKPAVM, FPPMPQPQ, LCLENLHLPLPLF, and LPPLVPFLKNPLM were found to be involved in the binding to the active sites of CEase, whereas all oth-
A

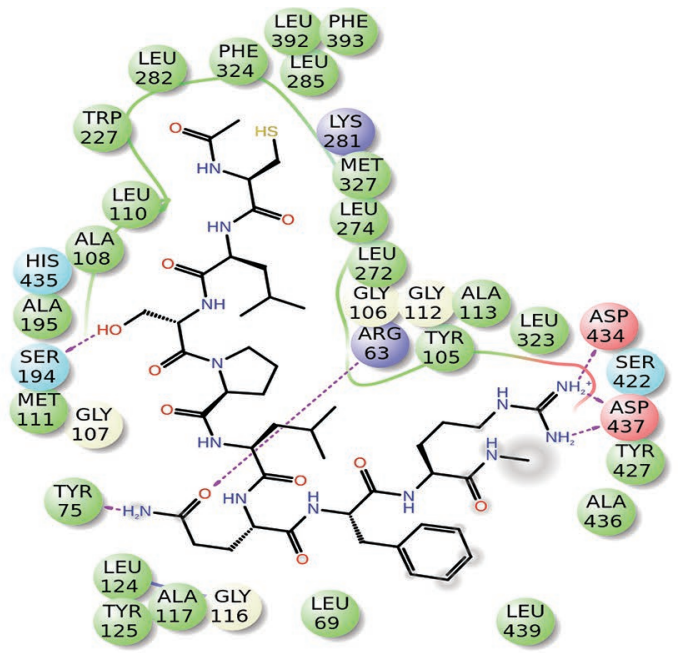

C

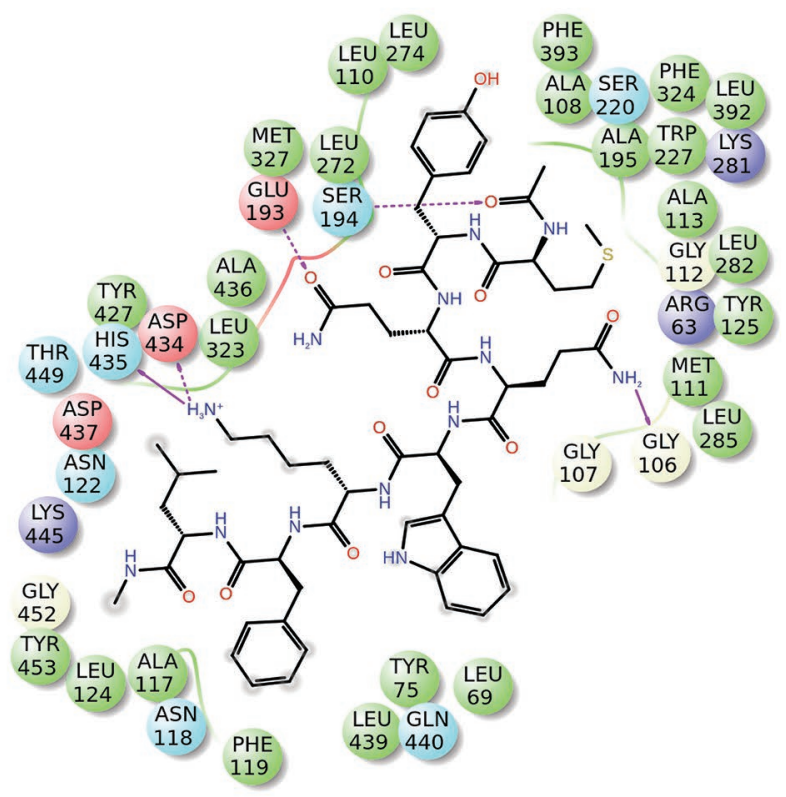

Charged (negative)

Charged (positive)
B

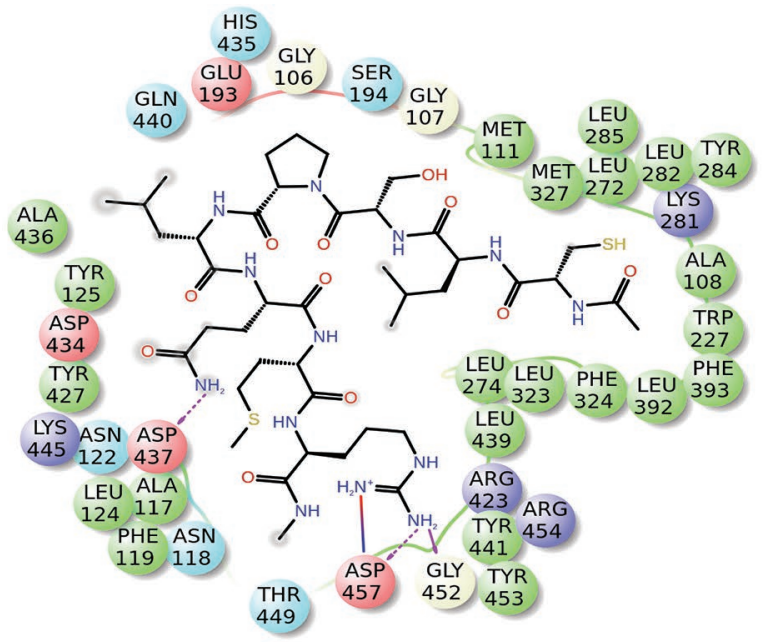

D

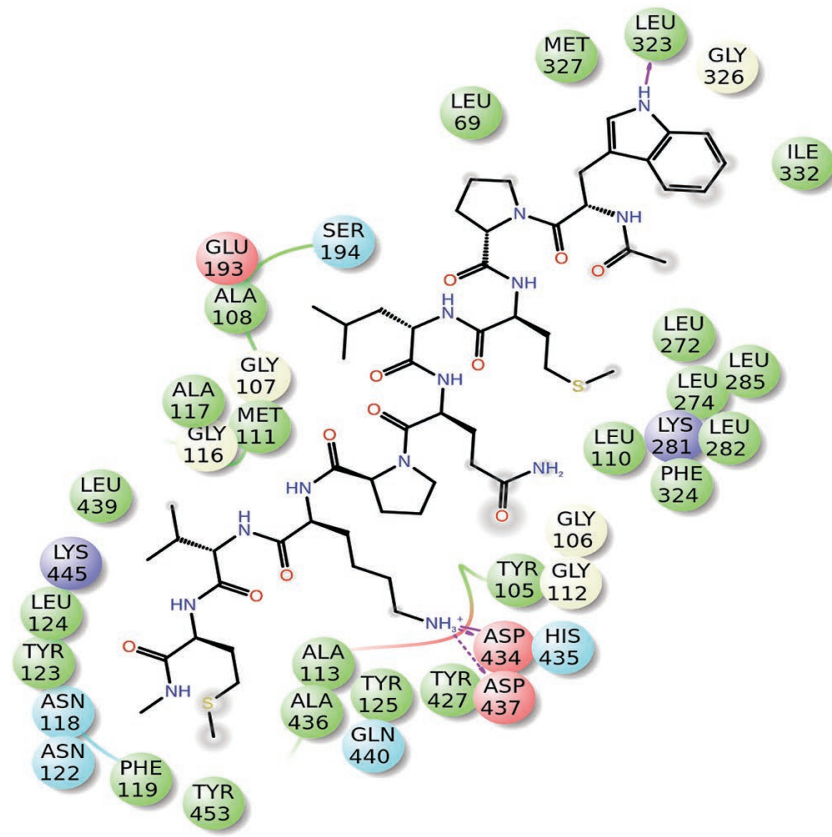

Glycine

Salt bridge

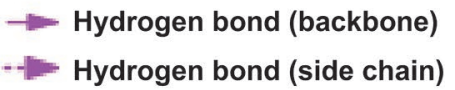

Figure 2. Interaction of cholesterol esterase with potential bioactive peptides: (A) CLSPLQFR, (B) CLSPLQMR, (C) MYQQWKFL, and (D) WPMLQPKVM. 
A
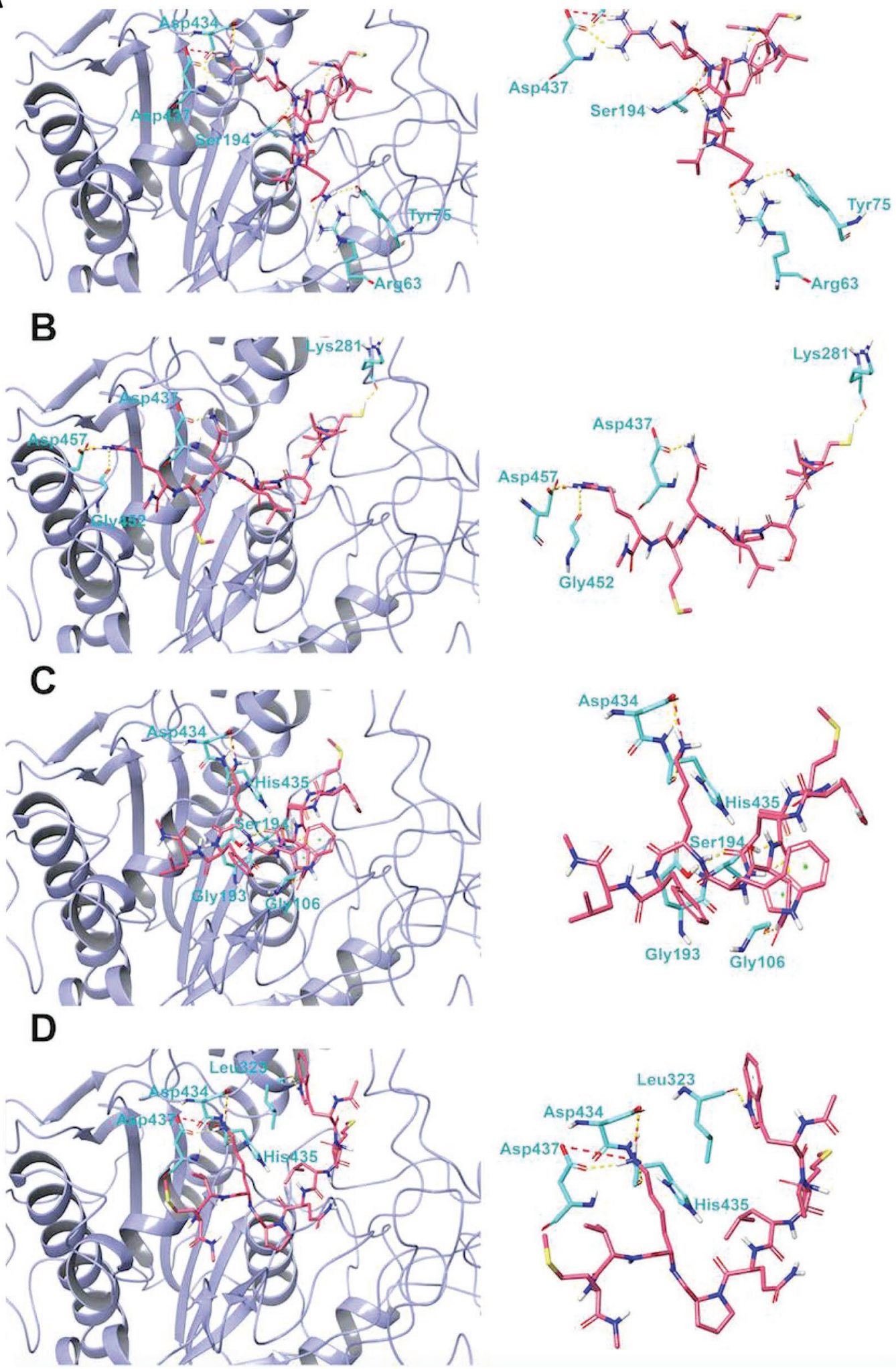

Figure 3. Docked poses and interaction of cholesterol esterase (CEase) with peptides (A) CLSPLQFR, (B) CLSPLQMR, (C) MYQQWKFL, and (D) WPMLQPKVM, where hydrogen bonds are represented by yellow dotted lines and salt bridges are represented by red dotted lines. 
ers made a contact only with surface AA of enzymes. These peptides would be able to bind to the catalytic sites of CEase (i.e., Ala108 and Ala195).

The molecular docking analysis of the peptides with the active site of cholesterol esterase (RCSB Protein Data Bank ID: 1AQL) displayed docking and binding energy scores of the 16 peptides screened against CEase as shown in Table 3 . Results obtained showed 4 peptides (i.e., WPMLQPKVM, CLSPLQMR, MYQQWKFL, and CLSPLQFR from $\mathrm{P}_{9}$ ) had strong binding with CEase as represented by good docking scores and MMGBSA binding energies (Table 3). The GlideScores (Friesner et al., 2004) of WPMLQPKVM, CLSPLQMR, MYQQWKFL, and CLSPLQFR were $-9.89,-9.16$, -7.85 , and $-7.45 \mathrm{kcal} / \mathrm{mol}$, respectively. Good MMGBSA binding energies were obtained for the complexes of 1AQL with WPMLQPKVM $(-126.26 \mathrm{kcal} /$ mol), CLSPLQMR (-119.26 kcal/mol), MYQQWKFL $(-125.72 \mathrm{kcal} / \mathrm{mol})$, and CLSPLQFR $(-121.96 \mathrm{kcal} /$ $\mathrm{mol})$. Figure 1 shows an interaction of potential CEase inhibitory peptides (CLSPLQMR) at an active site of CEase. All 4 peptides formed hydrogen bonds with one of the catalytic triad residues. Peptide CLSPLQFR formed a hydrogen bond with Ser194, and the other 3 peptides formed a hydrogen bond with His435. All 4 peptides displayed hydrogen and hydrophobic interactions with critical AA in these catalytic pockets of the active site of CEase (Figure 2A-2D). Additionally, all 4 peptides also produced hydrophobic interactions with Ala108, and CLSPLQMR and CLSPLQFR interacted with Ala195 (Figure 3A-3D). These 2 residues are involved in coordinating the oxyanion intermediate in the reaction (John et al., 2011). No previously published report exists on determining the CEase inhibitory properties of $\mathrm{CMPH}$ and the peptides, which might be potentially responsible for CEase inhibition. This is the first study that sheds light on the potential of camel milk protein hydrolysates to demonstrate potential inhibition of CEase and identifies the potent bioactive peptides with CEase inhibitory properties.

\section{CONCLUSIONS}

Camel milk remains an important part of the staple diet in Middle Eastern countries. Despite its popular health benefits, investigations on the health potential of camel milk remain limited. This study demonstrated that camel milk proteins constitute an interesting source of peptides inhibiting key metabolic enzymes related to disorders such as cholesterol assimilation. We observed that enzymatic hydrolysis released potent hypocholesterolemic peptides, and type of enzyme and time of hydrolysis have profound effects on the antihypercholesterolemic activities of the peptides released.
Hydrolysis of camel milk proteins with all enzymes until $6 \mathrm{~h}$ improved CEase inhibitory activity, whereas $9 \mathrm{~h}$ of treatment led to a reduction of this activity, confirming the importance of controlled hydrolysis. The important findings of this study were that the novel CEase inhibitory peptides were successfully identified, and the mechanisms of the inhibitory effects were well elaborated based on the structure-activity relationship and molecular docking analysis. Future work may involve purifying these peptides, investigating their potency in synthetic form, and checking their stability under simulated gastrointestinal conditions for their potential application in food formulations. These peptides also need to be tested in more challenging in vitro assays and animal models to better understand the mechanism of the action of the hypocholesterolemic effect.

\section{ACKNOWLEDGMENTS}

The authors are grateful to United Arab Emirates University for funding this research through a research grant (UPAR-31F094) awarded to the principal investigator, Sajid Maqsood, as well as University Sains Malaysia for an RUI grant (1001/CABR/8011045) awarded to Chee-Yuen Gan. Hina Kamal is acknowledged for providing technical assistance in the laboratory.

\section{REFERENCES}

Adisakwattana, S., J. Intrawangso, A. Hemrid, B. Chanathong, and K. Mäkynen. 2012. Extracts of edible plants inhibit pancreatic lipase, cholesterol esterase and cholesterol micellization, and bind bile acids. Food Technol. Biotechnol. 50:11-16.

Adisakwattana, S., J. Moonrat, S. Srichairat, C. Chanasit, H. Tirapongporn, B. Chanathong, S. Ngamukote, K. Mauml, and S. Sapwarobol. 2010. Lipid-Lowering mechanisms of grape seed extract (Vitis vinifera L.) and its antihyperlidemic activity. J. Med. Plants Res. 4:2113-2120.

Al-Shamsi, K. A., P. Mudgil, H. M. Hassan, and S. Maqsood. 2018. Camel milk protein hydrolysates with improved technofunctional properties and enhanced antioxidant potential in in vitro and in food model systems. J. Dairy Sci. 101:47-60.

Banks, J. L., H. S. Beard, Y. Cao, A. E. Cho, W. Damm, R. Farid, A. K. Felts, T. A. Halgren, D. T. Mainz, J. R. Maple, R. Murphy, D. M. Philipp, M. P. Repasky, L. Y. Zhang, B. J. Berne, R. A. Friesner, E. Gallicchio, and R. M. Levy. 2005. Integrated Modeling Program, Applied Chemical Theory (IMPACT). J. Comput. Chem. 26:1752-1780.

Bernstein, B. A., T. Richardson, and C. Amundson. 1977. Inhibition of cholesterol biosynthesis and acetyl-coenzyme A synthetase by bovine milk and orotic acid. J. Dairy Sci. 60:1846-1853.

Connolly, A., M. B. O'Keeffe, C. O. Piggott, A. B. Nongonierma, and R. J. FitzGerald. 2015. Generation and identification of angiotensin converting enzyme (ACE) inhibitory peptides from a brewers' spent grain protein isolate. Food Chem. 176:64-71.

Deck, L., and D. L. Vander Jagt. 2000. Inhibitors of cholesterol esterase. The University of New Mexico, assignee. US Pat. No. $5942631 \mathrm{~A}$

Dryakova, A., A. Pihlanto, P. Marnila, L. Curda, and H. Korhonen. 2010. Antioxidant properties of whey protein hydrolysates as measured by three methods. Eur. Food Res. Technol. 230:865-874. 
Fox, K. M., L. Wang, S. R. Gandra, R. G. Quek, L. Li, and O. Baser. 2016. Clinical and economic burden associated with cardiovascular events among patients with hyperlipidemia: A retrospective cohort study. BMC Cardiovasc. Disord. 16:13.

Friesner, R. A., J. L. Banks, R. B. Murphy, T. A. Halgren, J. J. Klicic, D. T. Mainz, M. P. Repasky, E. H. Knoll, M. Shelley, and J. K. Perry. 2004. Glide: A new approach for rapid, accurate docking and scoring. 1. Method and assessment of docking accuracy. J. Med. Chem. 47:1739-1749.

Heidrich, J. E., L. M. Contos, L. A. Hunsaker, L. M. Deck, and D. L. Vander Jagt. 2004. Inhibition of pancreatic cholesterol esterase reduces cholesterol absorption in the hamster. BMC Pharmacol. 4:5.

Ikeda, I., R. Matsuoka, T. Hamada, K. Mitsui, S. Imabayashi, A. Uchino, M. Sato, E. Kuwano, T. Itamura, and K. Yamada. 2002. Cholesterol esterase accelerates intestinal cholesterol absorption. Biochimica Biophysica Acta (BBA) - Gen. Sub. 1571134-44.

Iwaniak, A., P. Minkiewicz, and M. Darewicz. 2014. Food-originating ACE inhibitors, including antihypertensive peptides, as preventive food components in blood pressure reduction. Compr. Rev. Food Sci. Food Saf. 13:114-134

Jafar, S., H. Kamal, P. Mudgil, H. M. Hassan, and S. Maqsood. 2018. Camel whey protein hydrolysates displayed enhanced cholesteryl esterase and lipase inhibitory, anti-hypertensive and anti-haemolytic properties. Lebensm. Wiss. Technol. 98:212-218.

John, S., S. Thangapandian, S. Sakkiah, and K. W. Lee. 2011. Discovery of potential pancreatic cholesterol esterase inhibitors using pharmacophore modelling, virtual screening, and optimization studies. J. Enzyme Inhib. Med. Chem. 26:535-545.

Jrad, Z., J.-M. Girardet, I. Adt, N. Oulahal, P. Degraeve, T. Khorchani, and H. El Hatmi. 2014. Antioxidant activity of camel milk casein before and after in vitro simulated enzymatic digestion. Mljekarstvo/Dairy 644287-294.

Jung, T.-H., S.-S. Yun, W.-J. Lee, J.-W. Kim, H.-K. Ha, M. Yoo, H.-J. Hwang, W.-M. Jeon, and K.-S. Han. 2016. Hydrolysis by alcalase improves hypoallergenic properties of goat milk protein. Korean J. Food Sci. Anim. Resour. 36:516-522.

Kamal, H., S. Jafar, P. Mudgil, C. Murali, A. Amin, and S. Maqsood. 2018. Inhibitory properties of camel whey protein hydrolysates toward liver cancer cells, dipeptidyl peptidase-IV, and inflammation. J. Dairy Sci. 101:8711-8720.

Korhonen, H. 2009. Milk-derived bioactive peptides: From science to applications. J. Funct. Foods 1:177-187.

Li, J., R. Abel, K. Zhu, Y. Cao, S. Zhao, and R. A. Friesner. 2011. The VSGB 2.0 model: A next generation energy model for high resolution protein structure modeling. Proteins 79:2794-2812.

Mudgil, P., B. Baby, Y.-Y. Ngoh, H. Kamal, R. Vijayan, C.-Y. Gan, and S. Maqsood. 2019. Molecular binding mechanism and identification of novel antihypertensive peptides from camel milk protein hydrolysates. Lebensm. Wiss. Technol. 112:108193.

Mudgil, P., H. Kamal, G. C. Yuen, and S. Maqsood. 2018. Characterization and identification of novel antidiabetic and anti-obesity peptides from camel milk protein hydrolysates. Food Chem. 259:46-54

Myers, D., A. Schotte, H. Boer, and H. Borsje-Bakker. 1955. Studies on ali-esterases and other lipid-hydrolysing enzymes. 3. Inhibition of the esterases of pancreas. Biochem. J. 61:521-528.

Nagaoka, S., K. Miwa, M. Eto, Y. Kuzuya, G. Hori, and K. Yamamoto. 1999. Soy protein peptic hydrolysate with bound phospholipids decreases micellar solubility and cholesterol absorption in rats and Caco-2 cells. J. Nutr. 129:1725-1730.
Nagaoka, S., Y. Futamura, K. Miwa, T. Awano, K. Yamauchi, Y. Kanamaru, K. Tadashi, and T. Kuwata. 2001. Identification of novel hypocholesterolemic peptides derived from bovine milk B-lactoglobulin. Biochem. Biophys. Res. Commun. 281:11-17.

Nielsen, P., D. Petersen, and C. Dambmann. 2001. Improved method for determining food protein degree of hydrolysis. J. Food Sci. 66:642-646.

Nongonierma, A. B., and R. J. FitzGerald. 2014. Susceptibility of milk protein-derived peptides to dipeptidyl peptidase IV (DPP-IV) hydrolysis. Food Chem. 145:845-852.

Nongonierma, A. B. C. Mazzocchi, S. Paolella, and R. J. FitzGerald. 2017. Release of dipeptidyl peptidase IV (DPP-IV) inhibitory peptides from milk protein isolate (MPI) during enzymatic hydrolysis. Food Res. Int. 94:79-89.

Nongonierma, A. B., S. Paolella, P. Mudgil, S. Maqsood, and R. J FitzGerald. 2018. Identification of novel dipeptidyl peptidase IV (DPP-IV) inhibitory peptides in camel milk protein hydrolysates. Food Chem. 244:340-348.

Salami, M., R. Yousefi, M. R. Ehsani, M. Dalgalarrondo, J.-M. Chobert, T. Haertlé, S. H. Razavi, A. A. Saboury, A. Niasari-Naslaji, and A. A. Moosavi-Movahedi. 2008. Kinetic characterization of hydrolysis of camel and bovine milk proteins by pancreatic enzymes. Int. Dairy J. 18:1097-1102.

Sastry, G. M., M. Adzhigirey, T. Day, R. Annabhimoju, and W. Sherman. 2013. Protein and ligand preparation: parameters, protocols, and influence on virtual screening enrichments. J. Comput. Aided Mol. Des. 27:221-234.

Schrödinger, L. 2014. Schrödinger Suite 2014-4 Protein Preparation Wizard, Epik version 3.0. Schrödinger LLC, New York, NY.

Singh, H., J. V. Singh, M. K. Gupta, P. Singh, S. Sharma, K. Nepali, and P. M. S. Bedi. 2017. Benzoflavones as cholesterol esterase inhibitors: Synthesis, biological evaluation and docking studies. Bioorg. Med. Chem. Lett. 27:850-854.

Siow, H.-L., and C.-Y. Gan. 2016. Extraction, identification, and structure-activity relationship of antioxidative and $\alpha$-amylase inhibitory peptides from cumin seeds (Cuminum cyminum). J. Funct. Foods 22:1-12.

Su, J., H. Wang, C. Ma, C. Liu, C. Gao, R. Nie, and M. R. Tanver Rahman. 2016. Hypocholesterolaemic mechanism of bitter melon aqueous extracts via inhibition of pancreatic cholesterol esterase and reduction of cholesterol micellar solubility. Int. J. Food Sci. Nutr. 67:20-28

Tagliazucchi, D., S. Shamsia, and A. Conte. 2016. Release of angiotensin converting enzyme-inhibitory peptides during in vitro gastrointestinal digestion of camel milk. Int. Dairy J. 56:119-128.

Trabuco, L. G., S. Lise, E. Petsalaki, and R. B. Russell. 2012. PepSite: Prediction of peptide-binding sites from protein surfaces. Nucleic Acids Res. 40(W1):W423-W427.

Tulipano, G., D. Cocchi, and A. M. Caroli. 2012. Comparison of goat and sheep $\beta$-lactoglobulin to bovine $\beta$-lactoglobulin as potential source of dipeptidyl peptidase IV (DPP-4) inhibitors. Int. Dairy J. 24:97-101.

Watts, K. S., P. Dalal, R. B. Murphy, W. Sherman, R. A. Friesner, and J. C. Shelley. 2010. ConfGen: A conformational search method for efficient generation of bioactive conformers. J. Chem. Inf. Model. 50:534-546.

Zhong, F., X. Zhang, J. Ma, and C. F. Shoemaker. 2007. Fractionation and identification of a novel hypocholesterolemic peptide derived from soy protein alcalase hydrolysates. Food Res. Int. 40:756-762. 